\title{
DIMENSI CHARITY PERBANKAN SYARIAH
}

\author{
Saiful Bahri \\ Sekolah Tinggi Ilmu Ekonomi (STIE) Syariah Bengkalis, Riau, Indonesia \\ saifulbahri.usa@gmail.com \\ https://doi.org/10.46367/jps.v1i2.231
}

Received: Aug 03, 2020 Revised: Sep 21, 2020 Accepted: Sep 30, 2020 Published: Oct 12, 2020

\begin{abstract}
There are too many words of Allah in the Qur'an regarding donations and alms, at the same time it states that this charity instrument is a fundamental and principal variable in Islamic law which is actually a way of life. The urgency of charity is not only for individuals, but also very useful for financial institutions such as Islamic banking. With the intensification and extensification of charity, it is imperative that these financial institutions gain good blessings in the world, especially for bankers in the afterlife. With a simple method, namely descriptive analysis, this study describes as few facts as the authors know and understand in order to become a source of inspiration for the next good.
\end{abstract}

Keywords: Infak, Corporate Social Responsibility, Blessings.

\begin{abstract}
ABSTRAK
Terlalu banyak firman Allah SWT. dalam Al-Qur'an mengenai infak/sedekah, sekaligus menyatakan bahwa instrumen charity ini merupakan variabel fundamental dan prinsipil dalam syariat Islam yang notabene sebagai way of life. Urgensi charity tidak hanya bagi individu, tapi juga sangat berguna bagi lembaga keuangan seperti perbankan syariah. Dengan intensifikasi serta ekstensifikasi berderma meniscayakan lembaga keuangan ini mendulang keberkahan baik di dunia, apalagi untuk para bankir dalam urusan akhirat. Dengan metode sederhana, yakni analisis deskriptif, kajian ini memaparkan sekelumit fakta sebatas yang penulis ketahui dan pahami guna menjadi sumber inspirasi demi berbagai kebaikan berikutnya.
\end{abstract}

Kata Kunci: Infak, Corporate Social Responsibility, Berkah.

\section{PENDAHULUAN}

Sejatinya, Islam mengikat segala sistem kehidupan umatnya termasuk "kehidupan" perbankan syariah. Jadi, tidak ada kebebasan mutlak, tanpa batas. Hidup apalagi bisnis, pada hakikatnya tidak hanya berprinsip pada oportunisme atau profit oriented, tapi semestinya setiap insan menanamkan prinsip bahwa keberkahan juga merupakan variabel fundamental yang bertengger pada nilai-nilai selestial. Nilai-nilai seperti itu include dalam dimensi humanis (hablun minannas), dari langit (hablun minallah) untuk bumi. 
Apalah artinya banyak mendulang keuntungan tanpa terbangun kepedulian sesama sehingga sama sekali tidak mengundang keberkahan. Sama seperti dikatakan, apalah artinya banyak uang tapi tidak berkah, sehingga uang yang ada, tanpa disadari menguap secara cepat atau lambat. Juga seperti kandungan dalam salah satu ceramah agama yang menyebutkan bahwa tidak perlu banyak harta, tapi yang penting adalah harta yang dimiliki berkah, meskipun harta itu sedikit.

Sederet pertanyaan akan muncul berderivasi dari beberapa pertanyaan di atas, seperti: apalah arti hidup jika tidak memberi manfaat bagi orang lain; apalah arti kekayaan jika juga tidak bermanfaat bagi orang lain, apalagi harta itu tidak berguna bagi diri sendiri dan keluarga; apalah artinya perbankan syariah, jika mencuat, tapi tidak berkah dan menabur keberkahan bagi kehidupan ini. Ringkasnya, segala amal saleh yang berderivasi dari keimanan akan mendatangkan keberkahan. Paling tidak pemahaman ini menjadi fondasi dalam tumbuh-kembang perbankan syariah, baik nasional maupun global.

Mengenai karitas (charity) atau amal wiyata yang dalam terminologi alQur`an banyak disebut dengan infak dari kata tunfiqun, yunfiqun, anfaqtum, (yang kalian/mereka [telah] infakkan) juga merupakan ciri-ciri dari ketakwaan. Dan, hanya orang yang bertakwalah seperti tercantum dalam surah al-Baqarah [2] ayat 5 yang pada akhirnya mendapat hidayah Allah SWT. serta menjadi orangorang yang beruntung (muflihun). Keberuntungan (falah) yang dimaksud merupakan kesuksesan sejati yang (mungkin) tidak dapat dipahami oleh banyak orang.

Dalam pandangan orang banyak, orang yang sukses adalah mereka yang mempunyai jabatan strategis, punya rumah mewah, kendaraan mahal dan seterusnya dalam kacamata prestise dan materialisme. Sementara, dalam Islam bila merujuk pada ayat di atas, kesuksesan adalah mereka yang beruntung (muflihun). Orang-orang yang beruntung adalah mereka yang bertakwa. Dan, orang-orang yang bertakwa adalah mereka yang beriman kepada yang ghaib, mendirikan shalat, menafkahkan sebagian rezeki yang Allah SWT. limpahkan kepada mereka. Selanjutnya, mereka juga beriman kepada Al-Qur`an yang diturunkan kepada Rasulullah saw. dan juga beriman kepada kitab-kitab yang Allah swt. turunkan sebelumnya (Taurat, Zabur, Injil). Lalu, mereka juga meyakini akan datangnya hari akhirat. Mereka itulah yang mendapat petunjuk dari Allah swt. dan mereka adalah orang-orang yang beruntung (QS. Al-Baqarah [2] ayat 3-5). Itulah karakteristik kesuksesan sejati dalam Islam. Makanya sebanyak lima kali dalam sehari umat Islam dipanggil untuk meraih keberuntungan/kejayaan (hayya 'alal falah).

Dalam banyak aspek, perbankan syariah dinilai tidak kalah dengan perbankan konvensional, dari sisi infrastruktur, teknologi, manajemen informasi, juga layanan (service) dipandang cukup kompetitif. Bahkan dalam hal rasionalitas nasabah, sudah tentu institusi ini menjadi dambaan setiap muslim. Dari sisi market share pada gilirannya perbankan syariah juga dinilai mampu mendulang hasil maksimal. Tinggal lagi bagaimana lembaga keuangan ini lebih optimal dalam merealisasikan nilai-nilai ketakwaan dalam hal implementasi dan ektensifikasi charity. Karena, konsep yang terbangun selama ini mengenai lembaga keuangan ini adalah bahwa lembaga keuangan syariah pada hakikatnya tidak hanya berorientasi pada keuntungan (profit oriented), tapi juga diharapkan mampu berkontribusi pada kesejahteraan umat (social welfare). 
Lebih tepatnya, kajian ini berorientasi pada elaborasi dan implementasi Corporate Social Responsibility (CSR). di mana, sesuai topik dimaksud, bagaimana perbankan syariah membangun lebih banyak kepedulian kepada pihakpihak yang sengsara dan fakir ( $b a$ `isal faqir). Dengan demikian, niscaya dan semoga perjalanan dan dinamika lembaga yang juga dikenal dengan bank Islam ini, selain menuai profit juga mendulang keberkahan yang tiada henti.

\section{TELAAH LITERATUR}

Secara konkrit dan mendalam, urgensi karitas dapat dipahami dari rentetan firman Allah SWT. dalam Al-Qur'an Surah Al-Baqarah, di antaranya seperti pada ayat 261-274. Ayat-ayat itu sudah tentu menjadi petunjuk (hudan) bagi segenap manusia, termasuk segenap lembaga seperti perbankan syariah. Selain petunjuk, elaborasi firman allah swt. tersebut juga mengandung hikmah dan pelajaran yang konprehensif, radikal, juga universal (bayyinat). Allah SWT. berfirman dalam Qur'an Surah Al-Baqarah [2] ayat 262-264:

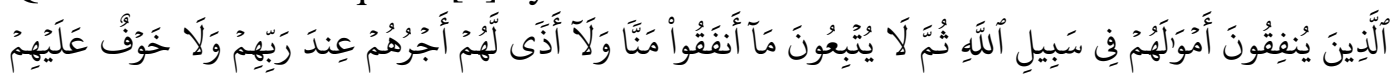

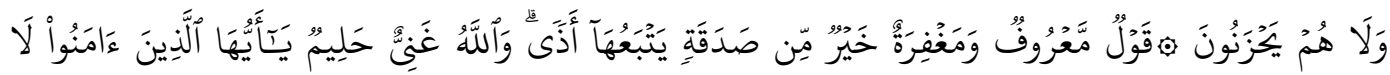

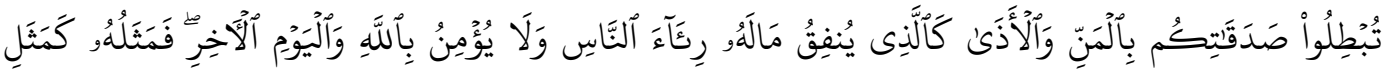

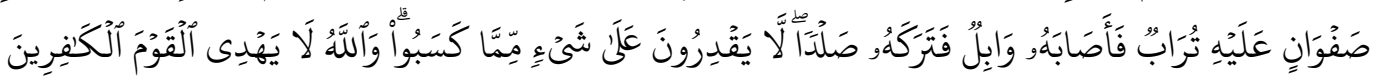
Artinya: "Orang-orang yang menafkahkan hartanya di jalan Allah, kemudian mereka tidak mengiringi apa yang dinafkahkannya itu dengan menyebut-nyebut pemberiannya dan dengan tidak menyakiti (perasaan si penerima). Mereka memperoleh pahala di sisi tuhan mereka. Tidak ada kekhawatiran terhadap mereka dan tidak pula mereka bersedih hati. Perkataan yang baik dan pemberian maaf lebih baik dari sedekah yang diiringi dengan sesuatu yang menyakitkan (perasaan si penerima). Dan Allah Maha Kaya lagi Maha Penyantun. Hai orangorang beriman, janganlah kalian menghilangkan (pahala) sedekahmu dengan menyebut-nyebutnya dan menyakiti (perasaan si penerima), seperti orang yang menafkahkan hartanya karena riya kepada manusia dan dia tidak beriman kepada Allah dan hari kemudian. Maka perumpamaan orang itu seperti batu licin yang di atasnya terdapat tanah, kemudian batu itu ditimpa hujan lebat, lalu menjadilah dia bersih (tidak bertanah). Mereka tidak menguasai sesuatu pun dari apa yang mereka usahakan; dan Allah tidak memberi petunjuk kepada orangorang yang kafir.

Sedangkan sedekah yang diniatkan untuk mendapatkan ridha Allah swt. serta untuk meneguhkan jiwa, terdapat pada Qur'an Surah Al-Baqarah [2] ayat 265:

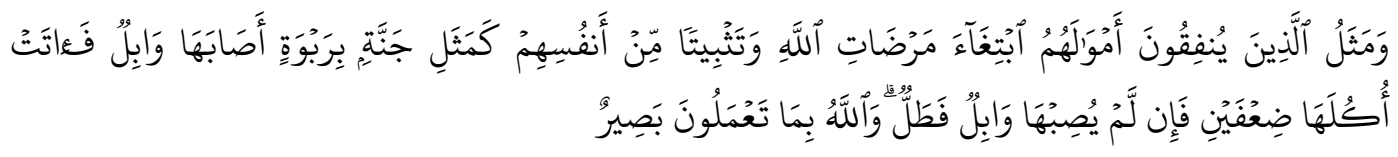

Artinya: "Dan perumpamaan orang-orang yang membelanjakan hartanya karena mencari keridhaan Allah dan untuk keteguhan jiwa mereka, seperti sebuah kebun yang terletak di dataran tinggi yang disiram oleh hujan lebat, maka kebun itu menghasilkan buahnya dua kali lipat. Jilka hujan lebat tidak menyiraminya, maka 
hujan gerimis (pun memadai). Dan Allah Maha Melihat apa yang kalian perbuat".

Selanjutnya, sungguh nikmat bila ayat sesudahnya disimak secara saksama:

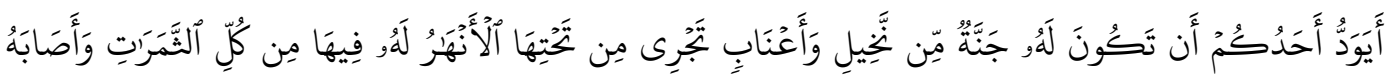

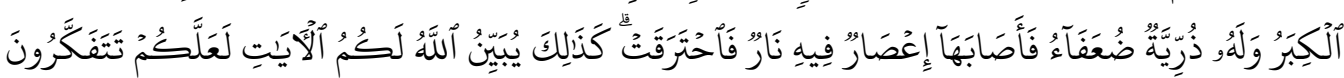

Artinya: "Apakah ada salah seorang di antara kalian yang ingin mempunyai kebun kurma dan anggur yang mengalir di bawahnya sungai-sungai; ia mempunyai dalam kebun itu segala macam buah-buahan, kemudian datanglah masa tuanya sedangkan ia mempunyai keturunan yang masih kecil-kecil. Maka kebun itu ditiup angin kencang yang mengandung api, lalu (kebun itu) terbakar. Demikian Allah menerangkan ayat-ayatnya kepada kalian semua supaya kalian memikirkannya" (QS. Al-Baqarah [2]: 266).

Setelah berbagai perumpamaan seperti tersebut di atas, lantas Allah swt. memerintahkan kepada orang-orang beriman seperti terdapat pada firman-Nya pada ayat sesudah itu:

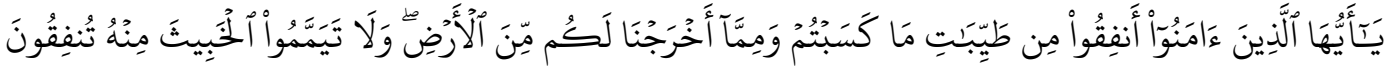

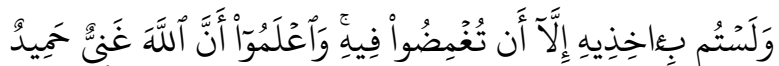

Artinya: "Wahai orang-orang yang beriman, nafkahkanlah (di jalan allah) sebagian dari hasil usaha kalian yang baik-baik dan sebagian dari apa yang Kami keluarkan dari bumi untuk kalian. Dan janganlah kalian memilih yang buruk-buruk lalu kalian nafkahkan dari padanya, padahal kalian sendiri tidak mau mengambilnya melainkan dengan memicingkan mata (tidak suka) terhadapnya. Dan ketahuilah bahwa Allah Maha Kaya lagi Maha Terpuji”. (QS. Al-Baqarah [2]: 267).

Berbagai keutamaan (fadhilah) yang Allah swt. janjikan bagi mereka yang rela (ikhlas) membelanjakan harta mereka fi sabilillah. Firman Allah SWT. dalam Qur'an Surah Al-Baqarah [2] ayat 268-272:

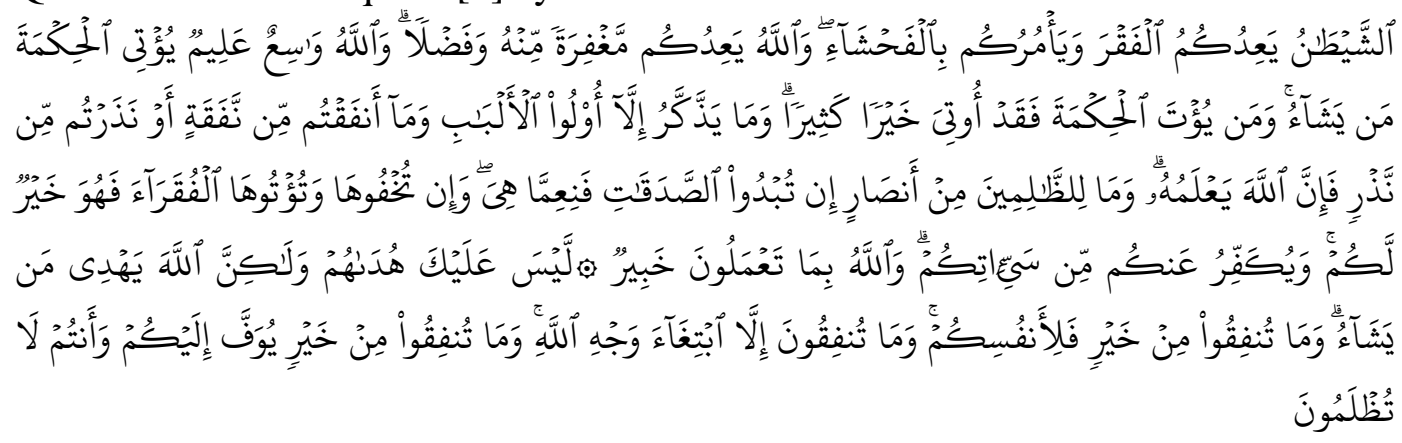

Artinya: "Syaitan menjanjikan (menakut-nakuti) kamu dengan kemiskinan dan menyuruh kamu berbuat kejahatan (kikir), sedangkan Allah menjanjikan untukmu ampunan dan karunia-Nya. Dan Allah Maha Luas (karunia-Nya) lagi Maha Mengetahui. Allah menganugerahkan al-hikmah (pemahaman yang dalam tentang al-Qur'an dan as-sunnah) kepada siapa yang Dia kehendaki. Dan siapa yang dianugerahi hikmah itu, ia benar-benar telah dianugerahi karunia yang banyak. Dan hanya orang-orang yang berakallah yang dapat mengambil pelajaran (dari firman Allah). Apa saja yang kamu nafkahkan atau apa saja yang kamu nazarkan, maka sesungguhnya Allah Maha Mengetahuinya. Orang-orang 
yang berbuat zalim tidak ada seorang penolongpun baginya. Jika kamu menampakkan sedekah (mu) maka itu adalah baik sekali. Dan jika kamu menyembunyikannya dan kamu berikan kepada orang-orang fakir, maka menyembunyikan itu lebih baik bagimu. Dan Allah akan menghapuskan bagi kamu sebagian kesalahan-kesalahanmu; dan Allah Maha Mengetahui apa yang kamu kerjakan. Bukanlah keajibanmu menjadikan mereka mendapat petunjuk, akan tetapi Allah lah yang memberi petunjuk (memberi taufik) siapa yang dikehenaki-Nya. Dan apa saja harta yang baik yang kamu nafkahkan (di jalan Allah), maka pahalanya itu untuk kamu sendiri. Dan janganlah kamu membelanjakan sesuatu melainkan karena mencari keridhaan Allah. Dan apa saja harta yang baik yang kamu nafkahkan, niscaya kamu akan diberi pahalanya dengan cukup, sedangkan kamu sedikitpun tidak akan dianiaya (dirugikan)”.

Maka, orang ataupun sebuah lembaga yang membelanjakan hartanya (aset) di jalan Allah swt. pada muaranya, mereka akan mendulang pahala dari-Nya, lalu mereka tidak akan pernah merasakan kekhawatiran terhadap keadaan apapun dan mereka tidak akan merasakan kesedihan dalam kondisi bagaimanapun. Firman Allah pada Qur'an Surah Al-Baqarah [2] ayat 273-274:

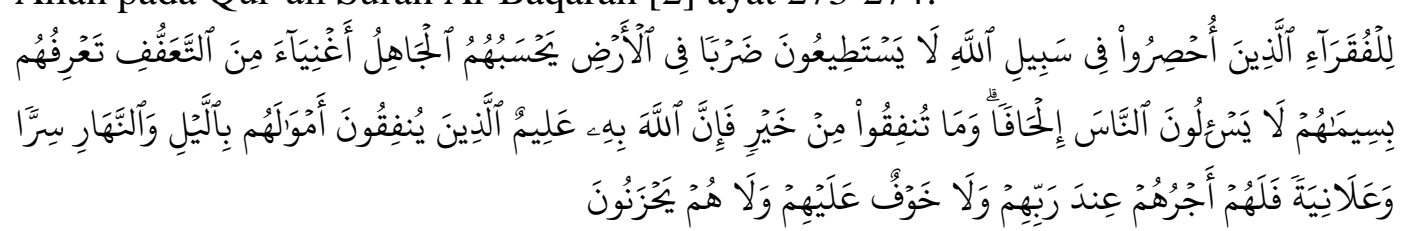

Artinya: "(Berinfaklah) kepada orang-orang fakir yang terikat (oleh jihad) di jalan Allah; mereka tidak dapat berusaha di muka bumi; orang yang tidak tahu menyangka bahwa mereka adalah orang kaya karena memelihara diri dari meminta-minta. Kamu kenal mereka dengan melihat sifat-sifatnya. Mereka tidak meminta kepada orang lain secara mendesak. Dan apa saja harta yang baik yang kamu nafkahkan (di jalan Allah), maka sesungguhnya Allah Maha Mengetahui. Orang-orang yang menafkankan hartanya di malam dan di siang hari secara tersembunyi dan terang-terangan, maka mereka mendapat pahala di sisi Tuhannya. Tidak ada kekhaatiran terhadap mereka dan tidak (pula) mereka bersedih hati".

Rentetan panjang ayat mengenai infak/nafkah tersebut di atas dapat dipahami sebagai pengantar ayat riba sesudahnya (QS. Al-Baqarah [2]: 275). Dan, sejatinya, firman Allah SWT. pada ayat ini lah yang menjadi fondasi tumbuhkembang perbankan dan lembaga keuangan syariah global.

Allah SWT. Maha Pemurah/Pengasih (Rahman) dan Maha Penyayang (Rahim) atau Maha Pemberi Rahmat (kasih/sayang). Sehingga Rasulullah saw. berpesan agar umat beliau bersahaja dalam beribadah dan tidak berlebihan sampai memaksa kemampuan diri. Karena, Allah swt. akan memasukkan umat Islam atau orang-orang beriman ke surga-Nya bukan karena ibadah mereka yang tidak seberapa itu bila dibanding dengan sifat Rahman-Nya allah swt. Subhanallah wa bihamdihi, subhanallahil 'Azhim! Beliau bersabda dalam Hadits yang diriwayatkan Imam Bukhari: “...Saddidu wa qarribu..." yang bermaksud, hendaklah kalian bersahaja dalam beribadah (Zabidi 2008).

Dengan demikian, jika Allah swt. dengan kehendak-Nya memberi kemurahan kepada hamba-Nya yang Ia kehendaki (yarzuqu man yasya'), lantas mengapa manusia menutup kemurahan itu sesamanya? Atau 'jalan sempit' itu 
merupakan sifat kikir manusia yang juga Allah swt. firmankan dalam al-Qur`an bahwa manusia itu sangat kikir (innal insana qaturo). Na'udzubillah min dzalik!

Menurut Veithzal Rivai (2010, 39), beberapa contoh dari perbedaan antara sistem bank Islam dan bank konvensional salah satu di antaranya adalah zakat. Bank Islam sudah tentu berhubungan erat dengan zakat, sementara bank konvensional sama sekali tidak. Dan, perlu dicatat di sini bahwa zakat merupakan salah satu bentuk dari infak/nafkah (spending).

Mengenai aspek keberkahan dalam suatu usaha atau bisnis, Zamir Iqbal (2007, 43) mengemukakan bahwa: "An important factor in the incentive system of Islam is the concept of barakah, which serve of the material inducement for the individual to follow the part of proper conduct."

\section{PEMBAHASAN}

Pada banyak literatur tentang perbankan syariah, kajian mengenai charity atau filantropi bisa dikatakan sangat susah ditemukan. Kebanyakan penulis hanya berkonsentrasi pada sistem dan praktik perbankan syariah. Sementara, subjek mengenai 'ibadah sosial' itu seakan-akan terlupakan atau dianggap tidak (begitu) penting.

Dalam konteks perusahaan, variabel tersebut menjadi program yang (mungkin) fundamental. Mereka menjadikan dan menyebut tugas mereka terhadap masyarakat dengan Corporate Social Responsibility (CSR). Dari program ini dan dari elemen atau mekanisme Public Relation (PR), mereka ingin berbenah dan berkontribusi lebih banyak untuk bangsa dan negara.

Bagaimana dengan perbankan syariah? Sudah tentu lembaga keuangan umat ini tidak mau ketinggalan. Dan, (mungkin) banyak program bakti sosial dan ajang 'berbagi' diluncurkan sebagai bukti kepedulian mereka terhadap masyarakat atau umat. Terlebih lagi dalam hal literasi mengenai sistem dan produk keuangan syariah, sudah tentu program seperti itu membumi sedemikian rupa.

Tinggal lagi, bagaimana lembaga ini lebih mengintensifikasi serta mengekstensifikasi program 'berbagi sesama' agar bank syariah dimaksud dikenang dan didamba oleh umat. Sehingga bank syariah pada akhirnya memenangi dan merebut hati masyarakat.

Mengapa Allah swt. mewajibkan umat Islam untuk membayar zakat dan menganjurkan mereka untuk bersedekah? Karena, pertama: kedua instrumen karitas itu merupakan manifestasi dari sifat berbagi sesama, seperti sifat terpuji Allah swt. yang Maha Pemberi/Pengasih (Rahman) kepada setiap hamba yang Ia kehendaki. Kedua: karena harta atau aset bagi siapa pun pada hakikatnya merupakan milik ar-Rahman. Dia Maha pemberi, jangan sampai sebagian dari pemberian-Nya tidak diberi (lagi) kepada orang lain, terlebih lagi bagi mereka yang sangat membutuhkan. Sehingga rezeki itu tersekat oleh karena sifat kikir manusia yang sangat bertentangan dengan sifat Rahman-Nya Allah swt.

Ketiga: dengan berzakat atau berinfak, rezeki akan mengalir sedemikian rupa, sehingga kekayaan tidak hanya terkonsentrasi atau tertumpuk di antara golongan kaya atau kaum borjuis saja (QS. Al-Hasyr [59]: 7). Jika itu terjadi, lantas, siapa lagi yang akan berpihak kepada kaum marginal atau proletar? Parahnya lagi jika kebanyakan bisnis menjadikan orang kaya sebagai orientasinya 
(Bahri, 2016: 117), sudah tentu bisnis itu tidak mendasari programnya sebagai rahmatan lil 'alamin.

Selain rasionalitas seperti di atas bahwa instrumen seperti zakat akan membersihkan jiwa dan raga bagi mereka yang menunaikannya (tuthahhiruhum wa tuzakkihim biha), merupakan ruh dari pensyariatan amalan tersebut.

Dengan demikian, apa yang menjadi hak dan kewajiban serta anjuran bagi setiap individu, juga berlaku bagi setiap entitas seperti perbankan syariah. Seperti halnya pajak, terdapat wajib pajak individu (perorangan) dan wajib pajak badan atau perusahaan. Jadi, urgensi untuk bermurah hati bagi individu beriman (mukmin) juga berlaku pada perbankan syariah.

Orang yang pemurah atau juga disebut dengan murah hati atau ringan tangan akan selalu dikenang dengan sebutan itu. Sementara, orang yang kikir atau bakhil juga akan terus diingat dengan sifat jelek tersebut.

Beberapa fakta membuktikan hal di atas, ternyata tokoh yang pemurah dan sering berbagi rezeki kepada siapa saja selalu langgeng dan melenggang pada posisinya. Sementara, tokoh pelit yang acap kali 'makan sendiri' selalu tersandung 'batu terjal dan kerikil' pada jalannya. Maka, dapat dipahami, sifat murah hati pada gilirannya akan mengundang murah rezeki.

Jika bank syariah dikenal oleh umat sebagai lembaga keuangan yang 'ringan tangan' dalam menabur rezeki, sudah tentu pada muaranya institusi itu akan mendulang hasilnya, bukan hanya profit, tapi juga keberkahan yang selama ini menjadi dambaan setiap insan.

Firman Allah SWT. mengenai urgensi infak/sedekah seperti dikemukakan sebelumnya tersurat berbagai pelajaran baik dan bermanfaat (mau'izhah hasanah), di antaranya adalah pertama, yaitu mengenai etika berinfak. Mereka yang berinfak/bersedekah tidak boleh menyebut-nyebut (karena riya') atas pemeberiannya. Selain itu, si pemberi tidak boleh menyakiti perasaan si penerima.

Kedua, berinfak hendaklah hanya mengharap ridha Allah SWT. dan ketetapan diri mereka. Ketiga, yang diinfakkan/disedekahkan merupakan komoditas yang baik, bukan yang jelek atau sesuatu yang tidak berguna (useless). Keempat, jangan takut bangkrut apalagi jatuh miskin karena berinfak/bersedekah, karena itu hanya bisikan setan yang menakut-nakuti agar si penderma mengurungkan niatnya untuk beramal saleh.

Kelima, dengan berinfak/bersedekah, Allah SWT. menjanjikan keampunan atas dosa-dosa si penderma dan Dia akan melimpahkan karunia-Nya dengan begitu luas. Keenam, berinfak/bersedekah boleh secara terang-terangan (menampakkanya) dan lebih baik lagi secara sembunyi-sembunyi. Ketujuh, berinfak/bersedekah dengan sesuatu yang baik-baik maka pahalanya sudah tentu untuk si penderma yang mengharap ridha Allah SWT. lantas Dia akan mencukupkan kebutuhan orang itu. Dan, si penderma sama sekali tidak dirugikan (mengalami kerugian).

Kedelapan, si penderma hendaklah jeli menemukan orang-orang fakir, karena di antara mereka tidak suka menampakkan kesusahan yang mereka derita. Untuk itu, temukan juga sifat yang melekat pada diri mereka itu.

Kesembilan, orang yang berinfak/bersedekah baik di malam maupun siang hari, baik terang-terangan ataupun sembunyi-sembunyi akan mendapatkan pahala di sisi Allah swt. lalu mereka tidak akan merasakan kekhawatiran terhadap apapun 
dan mereka tidak akan pernah bersedih hati terhadap berbagai fenomena dan dugaan.

Berbagai keutamaan (fadhilah) yang disebut di atas merupakan representasi dan manifestasi dari keberkahan yang dimaksud dalam kajian ini. Perbankan syariah sudah tentu tidak akan pernah luput dari fadhilah Allah SWT. seperti tersebut di atas, jika suatu bank syariah misalnya, berkomitmen dan konsisten dalam mengimplementasikan dan merealisasikan aspek berbagi dan peduli sesama. Intensifikasi serta ekstensifikasi program CSR merupakan ujung tombak manifestasi dari perintah Allah swt. untuk berinfak/bersedekah.

Jadilah orang mulia hartawan dan dermawan, dan jadilah lembaga yang mulia, lembaga yang liquid, bonafit dan penderma. Karena, usaha terus berinfak/bersedekah merupakan salah satu ciri ketakwaan.

\section{KESIMPULAN}

Urgensi berinfak/bersedekah sama halnya implementasi CSR oleh perusahaan, meskipun konsep manusia tidak sebanding dengan syariat Islam. Paling tidak pandangan itu sebagai manifestasi baha berinfak/bersedekah menyirat hikmah dan fadhilah Allah SWT. yang melimpah. Intensifikasi dan ekstensifikasi berderma oleh perbankan syariah sejatinya merupakan hal fundamental dan prinsipil untuk terus direalisasikan, agar keberkahan yang selalu didambakan tercurah tiada henti.

\section{DAFTAR PUSTAKA}

Bahri, Saiful. 2016. Untuk Menggapai Karunia Tuhanmu. Yogyakarta: Deepublish.

Departemen Agama RI. 1990. Al-Qur'an al-Karim, Lajnah Pentashih Mushaf alQur'an, al-Qur'an dan Terjemahannya. Madinah: Mujamma' al-Malik Fahd.

Iqbal, Zamir dan Abbas Mirakhor. 2007. An Introduction To Islamic Finance: Theory and Practice. Singapore: Wiley \& Sons.

Rivai, Veithzal dan Arviyan Arifin. 2010. Islamic Banking. Jakarta: Bumi Aksara. Zabidi, Imam Az. 2008. Ringkasan Shahih Bukhari. Mukhtashar Shahih Bukhari. Jakarta: Mizan. 